\title{
Functional Interaction between the Hippocampus and Nucleus Accumbens Shell Is Necessary for the Acquisition of Appetitive Spatial Context Conditioning
}

\author{
Rutsuko Ito, ${ }^{1,3}$ Trevor W. Robbins, ${ }^{1}$ Cyriel M. Pennartz, ${ }^{2}$ and Barry J. Everitt ${ }^{1}$ \\ ${ }^{1}$ Department of Experimental Psychology, University of Cambridge, Cambridge CB2 3EB, United Kingdom, ${ }^{2}$ Graduate School Neurosciences Amsterdam, \\ University of Amsterdam, Faculty of Science, Swammerdam Institute for Life Sciences, 1098 SM Amsterdam, The Netherlands, and ${ }^{3}$ Department of \\ Experimental Psychology, University of Oxford, Oxford OX1 3UD, United Kingdom
}

The nucleus accumbens (NAc) has been implicated in a variety of associative processes that are dependent on the integrity of the amygdala and hippocampus (HPC). However, the extent to which the two subregions of the NAc, the core and shell, form differentiated circuits within the amygdala- and hippocampal-ventral striatal circuitry remains unclear. The present study investigated the effects of selective excitotoxic lesions of the nucleus accumbens shell or core subregion on appetitive elemental cue and context conditioning, shown previously to be dependent on the basolateral amygdala and hippocampus, respectively. Rats were trained sequentially to acquire discrete conditioned stimulus-sucrose conditioning, followed by spatial context-sucrose conditioning in a place preference apparatus characterized by three topographically identical chambers, the chambers being discriminable only on the basis of path integration. NAc shell lesions selectively impaired the acquisition of conditioned place preference and the use of spatial information to retrieve information about a discrete cue, whereas, as expected, NAc core lesions attenuated the acquisition of cue conditioning compared with sham rats. In a subsequent experiment, disconnection of the HPC from the NAc shell using unilateral asymmetric lesions of each structure resulted in a pattern of impairment in place conditioning and context-dependent cue retrieval similar to that produced by NAc shell lesions. These data not only suggest that the NAc core and shell subregions subserve distinct associative processes but also that the NAc shell and HPC are important functional components of a limbic corticostriatal network involved in spatial context conditioning.

Key words: conditioned place preference; learning and memory systems; hippocampus; amygdala; nucleus accumbens; limbic

\section{Introduction}

Evidence from animal and human research suggests that the mammalian brain is organized into multiple, parallel neural systems that mediate different associative learning and memory processes (Hirsh, 1974; O'Keefe and Nadel, 1978; Squire, 1986; Packard et al., 1989; Kesner et al., 1993; Gaffan, 1994; Schroeder et al., 2002). The hippocampus (HPC) and amygdala occupy central positions in two of these systems, the former being integral to the processing of associative information embedded within a spatial context and the latter being critical for the processing of associations between emotive events and discrete stimuli (McDonald and White, 1993; Squire et al., 1993; Aggleton, 2000).

Relatively little is known about how information represented within these learning and memory systems may be integrated to enable behavioral output. Mogenson et al. (1980) suggested that the nucleus accumbens (NAc), an anatomically and functionally

Received Jan. 8, 2008; revised May 27, 2008; accepted May 27, 2008.

This work was supported by the Human Frontiers Science Program and completed within the Cambridge Behavioral and Clinical Neuroscience Institute, which is jointly supported by the Medical Research Council and Wellcome Trust. We thank Dr. Mike Aitken for his assistance in programming.

Correspondence should be addressed to Dr. Rutsuko Ito, Department of Experimental Psychology, University of Oxford, South Parks Road, 0xford OX1 3UD, UK. E-mail: rutsuko.ito@psy.ox.ac.uk.

D0I:10.1523/JNEUROSCI.1615-08.2008

Copyright $\odot 2008$ Society for Neuroscience $\quad$ 0270-6474/08/286950-10\$15.00/0 heterogeneous structure, could provide such a site of integration. Projections from the HPC and the basolateral amygdala (BLA) converge on similar regions and even identical cells, particularly in the NAc shell subregion, although the NAc core subregion also receives afferents from the BLA (Pennartz et al., 1994; Mulder et al., 1998; French and Totterdell, 2003). Furthermore, considerable evidence suggests that the NAc is important in the HPCdependent processing of spatial and contextual cues (Annett et al., 1989; Sutherland and Rodriguez, 1989; Seamans and Phillips, 1994; Riedel et al., 1997; Setlow and McGaugh, 1999) and that an intact NAc, and its dopaminergic innervation in particular, are necessary for BLA-mediated appetitive conditioning (Cador et al., 1989; Everitt et al., 1991) as well as discrete cue fear conditioning (Pezze et al., 2002).

There is, however, less consensus on the extent to which the different subregions of the NAc contribute to HPC and amygdala-dependent processes. Previous studies investigating the role of the NAc in appetitive spatial tasks, with few exceptions (Setlow and McGaugh, 1999), have not specifically targeted the NAc shell region (Annett et al., 1989; Sutherland and Rodriguez, 1989; Seamans and Phillips, 1994).

Here, we investigated the effects of specific NAc core and shell excitotoxic lesions on appetitive visual cue and contextual (spatial) conditioning using tasks shown previously to be BLA and 
HPC dependent, respectively (Ito et al., 2006). These tasks allow for greater control over the many competing stimuli available in the conditioning environment that could potentially guide the animal's appetitive behavior. In particular, correct performance in the contextual conditioning task depends on the use of spatial path integration, the animal's ability (attributed to the entorhinal-hippocampal system) to compute its current location in reference to an allocentric representation of the environment, based on an integration of its foregoing trajectory in space (McNaughton et al., 1991; Muller, 1996; O'Keefe, 1999; McNaughton et al., 2006) and not on discrete intramaze or extramaze cues (Ito et al., 2006). Having first established the presence of a specific behavioral deficit after NAc shell lesions in the spatial task that is also HPC dependent, the functional interaction between the HPC and NAc shell was investigated using an asymmetric disconnection procedure, in which a unilateral excitotoxic lesion of the HPC was combined with a contralateral lesion of the NAc shell (Gaffan and Harrison, 1987; Everitt et al., 1991; Floresco et al., 1997; Baxter et al., 2000; Setlow et al., 2002) to establish the serial dependency of information transfer between these brain regions.

\section{Materials and Methods}

\section{Subjects}

Subjects were 60 male Lister Hooded rats (Charles River) weighing between 300 and $330 \mathrm{~g}$ at the time of surgery. They were housed in pairs in a room held at a temperature of $21^{\circ} \mathrm{C}$ under a reversed $12 \mathrm{~h} \mathrm{light/dark}$ cycle (lights off 9:00 A.M.). Water was available ad libitum, but, after recovery from surgery, food (laboratory chow; Purina) was restricted to $18 \mathrm{~g}$ of lab chow per day, sufficient to maintain preoperative body weight and growth. All experiments were performed during the dark phase, between 9:00 A.M. and 7:00 P.M. and in accordance with the United Kingdom 1986 Animals (Scientific Procedures) Act Project License 80/1767.

\section{Surgery}

In all surgical procedures, animals were anesthetized with Avertin [10 g of 99\% 2,2,2-tribromoethanol (Sigma-Aldrich) in $5 \mathrm{~g}$ of tertiary amyl alcohol and $450 \mathrm{ml}$ of PBS (Dulbecco "A"; Unipath) in $40 \mathrm{ml}$ of absolute alcohol and $1 \mathrm{ml} / 100 \mathrm{~g}$ body weight, i.p.] and placed in a stereotaxic frame (David Kopf Instruments) with the incisor bar set at $-3.3 \mathrm{~mm}$ below the interaural line. A $1 \mu$ l syringe (SGE) was then lowered into the NAc core, shell, or HPC, and the neurotoxin was infused bilaterally or unilaterally for disconnection lesions. For NAc core lesions, $0.3 \mu$ l of 0.09 M quinolinic acid (Sigma-Aldrich) buffered to $\mathrm{pH}$ 7.3-7.4 in 0.1 $\mathrm{m}$ sterile phosphate buffer (sterile PB) was infused over $1 \mathrm{~min}$ in each hemisphere according to our established methodology (Parkinson et al., 1999b) using the following coordinates (in mm from bregma): anteroposterior (AP), +1.2 ; lateral (L), \pm 1.8 ; dorsoventral (DV), -7.1 from the skull surface (SS). The infusion cannula was left in place for an additional $5 \mathrm{~min}$ to allow complete diffusion of the toxin from the tip. For NAc shell lesions, three separate infusions of $0.09 \mathrm{M}$ NMDA (Sigma-Aldrich) buffered to $\mathrm{pH} 7.4$ using $0.1 \mathrm{M}$ sterile $\mathrm{PB}$ were made at different points along the DV axis in each hemisphere (in mm): (1) $0.2 \mu \mathrm{l}$ at $\mathrm{AP}+1.6, \mathrm{~L} \pm 1.1, \mathrm{DV}-7.8$ (SS), followed by 3 min diffusion time; (2) $0.1 \mu \mathrm{l}$ at $\mathrm{AP}+1.6, \mathrm{~L} \pm 0.9, \mathrm{DV}$ -7.2 and left for diffusion for $2 \mathrm{~min}$; and (3) $0.1 \mu \mathrm{l}$ at AP $+1.6, \mathrm{~L} \pm 0.9$, DV -6.5 and left for diffusion for $2 \mathrm{~min}$. Sham control groups $(n=10$ for experiment 1 ) were treated identically to the lesion groups, except that they received injections of $0.1 \mathrm{M}$ sterile $\mathrm{PB}$, instead of the toxin. For unilateral HPC lesions, six separate infusions of $0.09 \mathrm{M}$ NMDA buffered to $\mathrm{pH} 7.4$ using $0.1 \mathrm{M}$ sterile $\mathrm{PB}$ were made (Ito et al., 2005) at the following points (in $\mathrm{mm}$ ): (1) $0.4 \mu \mathrm{l}$ at $\mathrm{AP}-2.8, \mathrm{~L} \pm 1.6, \mathrm{DV}-3.3$, and (2) $0.4 \mu \mathrm{l}$ at $\mathrm{AP}-4.2, \mathrm{~L} \pm 2.6, \mathrm{DV}-3.0$, each followed by 4 min diffusion time; (3) $0.2 \mu \mathrm{l}$ at $\mathrm{AP}-4.8, \mathrm{~L} \pm 4.8, \mathrm{DV}-6.0$, (4) $0.2 \mu \mathrm{l}$ at $\mathrm{AP}-5.3, \mathrm{~L}$ $\pm 4.6, \mathrm{DV}-4.2$, (5) $0.2 \mu \mathrm{l}$ at $\mathrm{AP}-5.3, \mathrm{~L} \pm 4.6, \mathrm{DV}-6.0$, and (6) $0.2 \mu \mathrm{l}$ at $\mathrm{AP}-5.8, \mathrm{~L} \pm 4.6, \mathrm{DV}-4.2$, each followed by $2 \mathrm{~min}$ diffusion time. After surgery, rats were allowed a recovery period of at least $7 \mathrm{~d}$ before behavioral testing, with food available ad libitum.

\section{Apparatus}

All behavioral training and testing took place in a purpose-built automated place preference apparatus (Med Associates), placed on a rotatable table elevated $1 \mathrm{~m}$ above the floor. The maze consisted of a central, white polyvinyl chloride (PVC) floored compartment in the shape of an equilateral triangle (side $38.1 \mathrm{~cm}$ ) and three connecting chambers identical in size $(38.1 \times 38.1 \times 20 \mathrm{~cm})$ and other physical features. An archway ( $10 \mathrm{~cm}$ high $\times 9 \mathrm{~cm}$ wide) served as the entrance to each chamber and could be closed off with a manually operated guillotine door. Each wall ( $0.7 \mathrm{~mm}$ thick gray PVC) of the chamber contained a centrally located recessed well consisting of a tray into which sucrose could be delivered, a $1.8 \mathrm{~W}, 17 \mathrm{~V}$ light directly above the tray (conditioning light), and nose-poke sensor (Fig. 1). Other features of the chamber included a stainless steel grid rod floor consisting of $3 / 16$ inch $(4.8 \mathrm{~mm})$ rods, placed above a $38.0 \times 38.0 \mathrm{~cm}$ stainless steel tray, three infrared beams placed at the entrance, 10 and $28 \mathrm{~cm}$ away from the entrance, and a $2.5 \mathrm{~W}, 24 \mathrm{~V}$ chamber light located in the top left corner of the entrance wall. The entire maze was covered with red translucent Plexiglas lids, to allow recording of behavior (via a video camera mounted above the apparatus) but prevent rats from seeing extramaze cues once inside the place preference chambers (except for the reference light on initial placement in the apparatus, see below). The apparatus was controlled and behavioral data collection achieved using the Whisker software written by Rudolf Cardinal and Mike Aitken (University of Cambridge, Cambridge, UK).

The place preference apparatus itself was placed in a testing room containing a bright reference light $(60 \mathrm{~W})$ in the right corner as the sole light source. All other extramaze objects remained in the same position in the room for the duration of the experiment. Radio noise was played beneath the apparatus to mask any unwanted auditory cues. The floor and walls of the apparatus were wiped down with ethanol solution after each session to eliminate any odor traces.

\section{General procedure}

At the start of each testing day, all rats were transferred from their home cage to a holding room located $\sim 15$ feet away from the testing room. Each rat was then transported in an opaque carrier box to the testing room. Once inside the room, each rat was placed on an elevated platform to the right of the door for $1 \mathrm{~min}$ where it could freely view the room, including the reference light, and orient itself. The aim of this orientation phase was to allow the rat's allocentric navigational system to align itself with respect to room cues and enable self-localization (McNaughton et al., 1991, 2006; Gothard et al., 1996; Muller, 1996; O'Keefe, 1999). The rat was then placed into the central compartment of the apparatus from one of three directions (south, north-east, and north-west) chosen at random, ensuring that it did not have the same entry direction for two consecutive sessions. After $1 \mathrm{~min}$ in the central compartment, all three guillotine doors were opened to let the rat explore all chambers. The reference light in the room was then switched off, with the chamber lights within the apparatus providing the only illumination in the testing room. The experimenter then left the room, closed the door, and observed the rat from an adjacent control room. The rationale behind leaving the reference light on when the rat was placed in the apparatus was to ensure a continued alignment of the rat's spatial navigational system to this external reference. After extinguishing this light, the rat had to rely on its internal path-integration capacity to identify the three compartments, because no local cues were available to distinguish them. Previous studies have shown that the entorhinal-hippocampal system strongly contributes to this capacity and continues to function even if landmarks are removed or room lights are extinguished (McNaughton et al., 1991, 2006; Gothard et al., 1996; Muller, 1996; O'Keefe, 1999). At the end of each training day, the place preference apparatus was rotated $120^{\circ}$ clockwise while occupying exactly the same position in relation to the rest of the room. This ensured that conditioning to individual chambers was minimized. These procedures were strictly adhered to from day to day it because was important that perceptual constancy between the place preference apparatus and external environment was maintained, such that the rats would learn to use the reference light as a consistent source of directional information. 
Experimental procedure (Fig. 1)

Habituation. All rats were given one $20 \mathrm{~min}$ habituation session in which they were free to explore all three chambers.

Cue conditioning. Rats were trained to associate a $15 \mathrm{~s}$ flashing light stimulus with the availability of $0.7 \mathrm{ml}$ sucrose solution delivered to a well by a software-operated infusion pump (Semat Technical) within a well. On the first day of training, a small amount $(\sim 0.5 \mathrm{ml})$ of sucrose was placed in all the wells to encourage subsequent exploration of the wells.

Sessions 1-3. In each daily session, rats received 30 contingent pairings of the sucrose solution [unconditioned stimulus (US)] and the flashing light stimulus [conditioned stimulus (CS)] positioned directly above the well, under a variable interval (VI) 20-60 s schedule. The 30 CS-US presentations took place in a different spatial context each day, with the starting context/chamber counterbalanced across rats (e.g., session 1 , chamber 1 ; session 2 , chamber 2 ; session 3 , chamber 3 ) and with each pairing being presented in one of three locations (wells within the chamber) in random order. Nevertheless, each trial could only be initiated by the first photobeam interruption in a chamber that was not rewarded in the previous trial so as to encourage exploration of all chambers during the training session. To increase the salience of the flashing light CS, all chamber lights were turned off during a trial. The session terminated at the end of the 30th trial and typically lasted $35 \mathrm{~min}$.

Sessions 4-6. In the second phase of cue conditioning, the CS-US presentations were no longer confined to one chamber. Instead, they could be located in any one of nine possible locations within the place preference apparatus (3 $\times 3$ wells in each chamber) in each trial. Although the presentation of the CS-US occurred in random order across the nine locations, it was ensured that the number of CS-US presentations per chamber was equal and that not more than two consecutive pairings occurred in one chamber within each session. Other session parameters remained the same as before.

CS probe test (session 7). This day was designed to test the acquisition of cue conditioning. Thirty CSs were presented on a VI 20-40 s schedule with the absence of sucrose, again in random but calculated order across the nine different locations. The trials in which the rat made a nose-poke response in the well while the CS was still flashing (15s) were classified as "correct" trials.

Place (spatial context) conditioning (sessions 8-15). In this part of the experiment, rats were trained to learn that the light CSs presented in one of three chamber locations were associated with the sucrose reward, but that the same light CSs presented in the other two chamber locations were not. As before, each daily session involved the presentation of 30 CSs in random order between the nine possible locations under a VI 20-60 s schedule. This time, however, only the CSs presented in a preassigned "positive" chamber location $(n=10)$ were rewarded. The other 20 CS presentations were no longer associated with reward. The noise of the pump that accompanies the delivery of sucrose was presented even in the unpaired contexts to ensure that it did not act as an inadvertent discriminative stimulus. The session terminated after the 30th CS presentation and typically lasted $45 \mathrm{~min}$. The number of approaches to the CS presented in the positive chamber locations (CS+) and the CS presented in the negative chamber locations (CS-) were recorded for each session.

Conditioned place preference test (session 18). Rats were given $15 \mathrm{~min}$ to

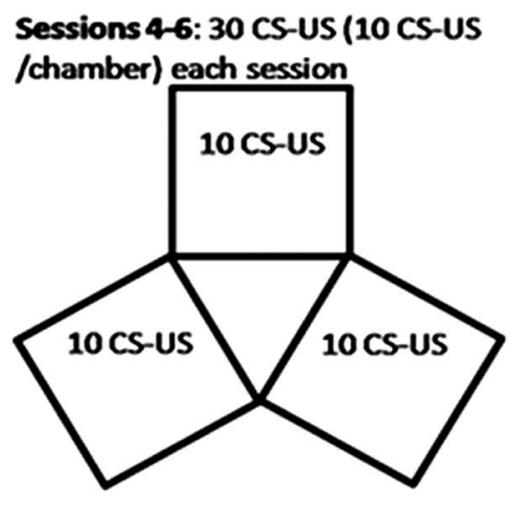

\section{Place (spatial context) conditioning}
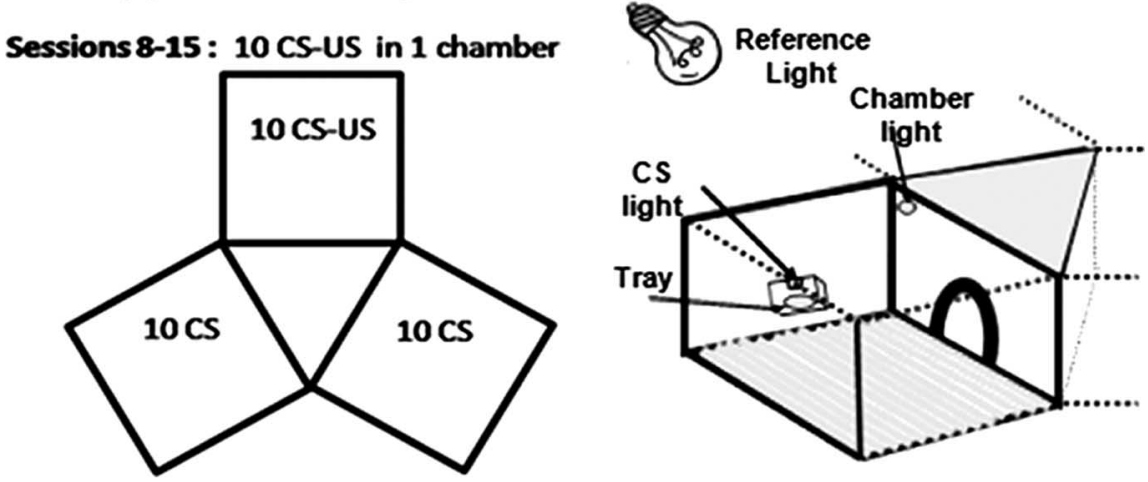

Figure 1. Cue and spatial context conditioning task. Cue conditioning: rats were presented with 30 CS-US pairings/session on a variable interval $20-60$ s schedule. For the first three sessions, the CS-US presentations were confined to the three wells in one chamber each day, with the starting chamber counterbalanced across rats (e.g., day 1, chamber 1; day 2, chamber 2; day 3, (sessions 4-6), the 30 (S-US presentations could be located in any one of nine possible well of the apparatus is shown in the bottom right, depicting the locations of the reference light, chamber light, and CS light. Note that only one of the three trays plus CS lights, present in the chamber, has been represented.

explore the entire apparatus in the absence of the CS and sucrose presentations. The time spent, locomotor activity, and the number of nose pokes made in each chamber location were recorded in 5 min bins.

\section{Histological procedure and assessment of lesions}

After completion of testing, all rats were anesthetized with sodium pentobarbitone (1.5 ml/animal, $200 \mathrm{mg} / \mathrm{ml}$ Euthatal; Rhone Merieux) and perfused intracardially via the ascending aorta with $0.01 \mathrm{M}$ PBS for $4 \mathrm{~min}$, followed by formaldehyde solution (4\% paraformaldehyde in PBS) for 6 min. Brains were then removed, stored in paraformaldehyde, and transferred to a $20 \%$ sucrose cryoprotectant solution on the day before sectioning. Coronal sections $(60 \mu \mathrm{m})$ of the brain were cut using a freezing microtome and then stained with cresyl violet to be viewed under the microscope for the verification of lesion placements, which were mapped onto standardized sections of the rat brain (Paxinos and Watson, 1997). In animals with lesions of the NAc shell, immunocytochemistry was performed on the sections for the visualization of the neuronal-specific nuclear protein (NeuN), using monoclonal antibodies (mAb 377; Millipore Bioscience Research Reagents) and a standard Vectatstain, avidinbiotin procedure.

\section{Data analysis}

All data were analyzed using the SPSS statistical package version 9.0. The total number of correct trials, mean latency to approach the CS during 


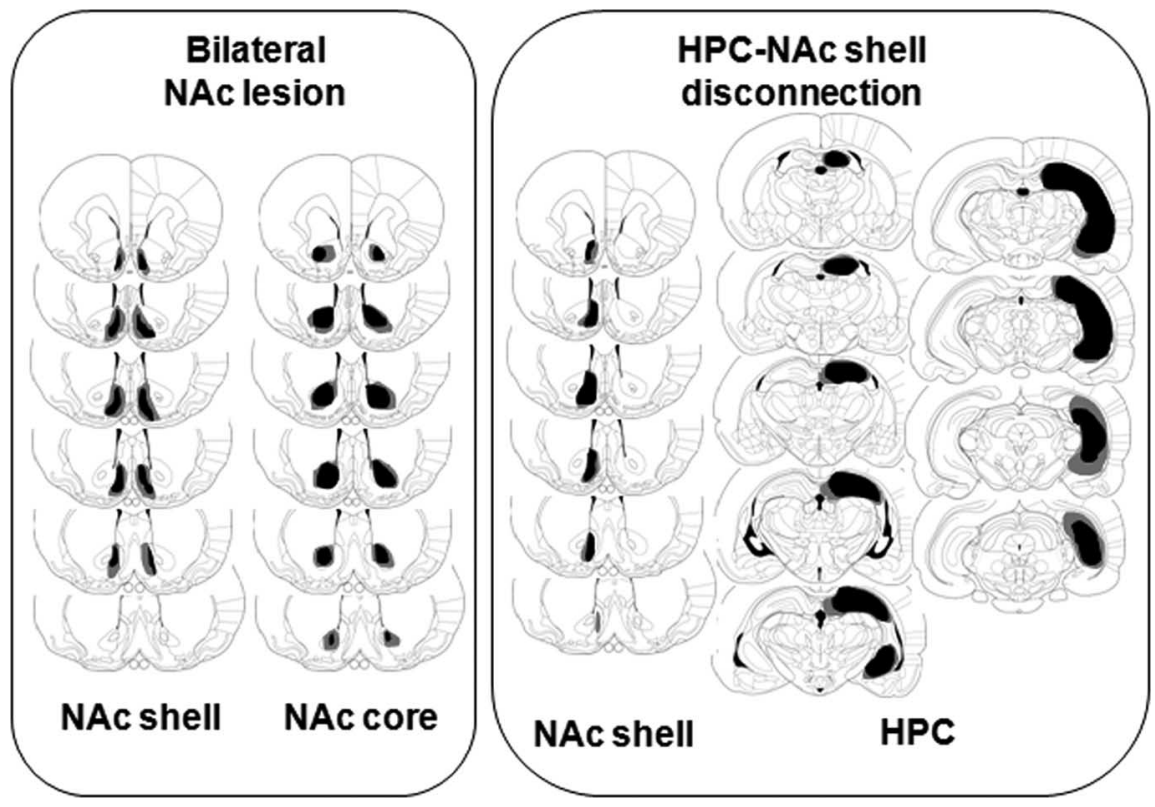

Figure 2. Schematic representation of quinolinic lesions of the NAc core, NMDA lesions of the NAc shell (left), and disconnection lesions of the NAc shell and HPC (right). Areas shaded in gray and black represent the largest and smallest extent of neuronal damage in a single animal, respectively.

eral damage to the overlying caudate-putamen. A total of 10 rats were included in the core-lesioned group and used in the behavioral data analysis. Bilateral and unilateral excitotoxic lesions of the NAc shell induced by NMDA caused neuronal damage in the caudomedial aspect of the shell subregion and extended rostrally from + 2.2 to $0.7 \mathrm{~mm}$ anterior to bregma. Data from two rats with evidence of bilateral lesion encroachment into the NAc core were excluded from analyses in experiment 1 , leaving a total of eight rats in the shelllesioned group. None of the data were excluded from experiment 2 on the basis of incomplete NAc shell lesion (unilateral shell lesion group, $n=8$; disconnection lesion group, $n=8$ ).

Unilateral excitotoxic lesions of the HPC extended rostrally from -1.8 to -6.7 $\mathrm{mm}$ posterior to bregma, encompassing all the hippocampal subfields and dentate gyrus of the dorsal and ventral HPC. Data from one rat in the disconnection lesion group were excluded on the basis of a partial HPC lesion that did not extend to the entire ventral HPC, leaving a total of seven

correct trials, nose pokes, and beam breaks recorded in each session during cue conditioning were subjected to repeated-measures ANOVA with lesion group as the between-subjects factor and session as the within-subjects factor. Data obtained during the context conditioning phase consisted of the number of approaches to CS+ (while the CS is being presented - maximum 10) and CS - (maximum 20 divided by 2 for equivalence with the CS+ approach) for each session. These were subjected to repeated-measures ANOVA with lesion group as the between-subjects factor and CS (CS+/CS-) and session as the withinsubject factors. An additional measure of the acquisition of discriminative approach behavior (difference score) was calculated by subtracting the number of approaches to the CS - from that to the CS+ in the disconnection experiment. Repeated-measures ANOVA was also conducted on these measures, with lesion group as the between-subject factor and difference score and session as the within-subject factors. Conditioned place preference was expressed as the amount of time spent in each of the three chambers and the central compartment within the first $5 \mathrm{~min}$ of the test, and repeated-measures ANOVA was conducted on these with lesion group as the between-subject factor and chamber as the within-subject factor. Separate one-way ANOVAs were conducted for each of the lesion group to assess the expression of place preference. When there was a significant violation of homogeneity of variance across groups for a repeated-measure design, as assessed by the Mauchly sphericity test, the Greenhouse-Geisser $\varepsilon$ test was used to calculate a more conservative $p$ value for each $F$ ratio. When simple one-way ANOVAs were conducted on confirmation of significant interactions, the $\alpha$ was adjusted using Sidak's method $\left(\alpha^{\prime}=1-(1-\alpha)^{1 / c}\right.$ (where $c$ is the number of within-experiment analyses).

\section{Results}

\section{Lesion assessment}

As shown in Figures 2 and 3, excitotoxic lesions of the NAc core induced by quinolinic acid extended rostrally from +2.5 to $+0.48 \mathrm{~mm}$ anterior to bregma. Neuronal damage in most cases was restricted to the area surrounding the anterior commissure but occasionally extended unilaterally to the caudate-putamen and to the lateral or ventromedial shell. Any rats with bilateral damage of this kind were excluded from data analysis. Thus, two rats were excluded from the study on the basis of extensive bilat- rats in the group. All rats in the unilateral HPC lesion group $(n=$ 6) were included in the data analysis.

\section{Effect of NAc core or shell lesions on cue conditioning}

The ability of sham-operated, NAc core and shell-lesioned rats to acquire an association between a discrete CS and sucrose availability (US) is shown in Figure $4 A$. Overall two-way ANOVA conducted on the acquisition data from all groups revealed significant pavlovian learning, as signified by an increase in the number of correct responses made during CS presentations across $6 \mathrm{~d}$ of cue conditioning (day effect, $F_{(5,125)}=118.67, p<$ $0.0001)$. There was, however, a significant lesion effect $\left(F_{(2,25)}=\right.$ $3.41, p<0.05)$ and a significant day $\times$ lesion interaction $\left(F_{(10,125)}\right.$ $=2.15, p<0.03)$ across the $6 \mathrm{~d}$ of conditioning, indicating that there were differences in the overall number of correct trials in the three lesion groups. Tukey's pairwise comparisons conducted on the mean number of correct trials during acquisition revealed that the NAc core-lesioned group achieved a lower number of correct trials compared with the sham-operated group $(p<$ $0.03)$. The numbers of correct trials shown by the sham and NAc shell-lesioned groups did not differ from each other $(p>0.48)$. Although there was a trend of NAc core-lesioned rats to be slower to approach the CS-US (Fig. $4 \mathrm{~B}$ ) during the correct trials compared with the sham group, this did not reach significance (no lesion effect, $\left.F_{(1,18)}=1.66, p=0.21\right)$. More notable, however, was the consistently and significantly decreased latency to approach the CS during correct trials in the NAc shell-lesioned group compared with the sham and core group (lesion effect, $\left.F_{(1,16)}=11.0, p<0.004\right)$.

The performance of the NAc core-lesioned and NAc shelllesioned groups on the CS probe day, however, was not significantly different from that of the sham group (independent samples $t$ test; core, $t=0.16, p<0.88$; shell, $t=-1.4, p<0.18$ ), suggesting that all groups eventually acquired the CS-US association.

Overall two-way ANOVA conducted on levels of locomotor 
activity (Fig. 4C) across six conditioning sessions yielded a significant effect of training session (session effect, $F_{(5,125)}=$ 11.0, $p<0.0001)$ and a significant session $\times$ lesion interaction $\left(F_{(10,125)}=2.74\right.$, $p<0.01)$. Additional one-way ANOVA for repeated measures showed that, whereas sham and NAc shell-lesioned rats showed significant increase in the level of locomotor activity across training (sham, $F_{(5,45)}=3.97, p<0.005$; shell, $F_{(5,35)}=$ 83.55, $p<0001)$, NAc core-lesioned rats did not $\left(F_{(5,45)}=1.05, p=0.40\right)$. There were significant group differences between the overall levels of locomotor activity during cue conditioning, as indicated by a significant main effect of lesion $\left(F_{(2,25)}=\right.$ $4.5, p<0.02$ ). Post hoc analyses revealed that locomotor activity was consistently and significantly elevated in the shelllesioned group compared with the shamoperated group $(p<0.02)$, whereas the locomotor activity levels of the corelesioned group were not significantly different from those of the sham-operated group during cue conditioning $(p>$ $0.14)$.

Overall two-way ANOVA conducted on the levels of general nose-poke responses across the six conditioning sessions revealed a significant main effect of lesion group $\left(F_{(2,25)}=5.42, p<0.01\right)$ but no lesion $\times$ session interaction $\left(F_{(10,125)}=\right.$ $0.68, p=0.74)$. Post hoc Tukey's pairwise comparisons indicated that shell-lesioned rats showed consistently higher levels of nose-poke behavior compared with shamoperated $(p<0.01)$ rats all throughout cue conditioning acquisition. In contrast, there were no differences between the nose-poke levels of sham-operated and core-lesioned rats $(p>0.83)$.

In summary, the acquisition of cue conditioning was attenuated in core-lesioned rats compared with the sham-operated group, an effect that was not accompanied by concomitant changes in general locomotor, or nose-poke behavior. NAc shelllesioned rats showed no apparent impairment in the acquisition of cue conditioning but did show significantly elevated levels of locomotor and nose-poke activities throughout most of the acquisition phase compared with the shamoperated rats.

\section{Effect of NAc core or shell lesions on spatial context conditioning}

Place-cue retrieval

This phase of the experiment (sessions 8-15) assessed the ability of shamoperated, NAc- and HPC-lesioned rats to use spatial contextual information to guide
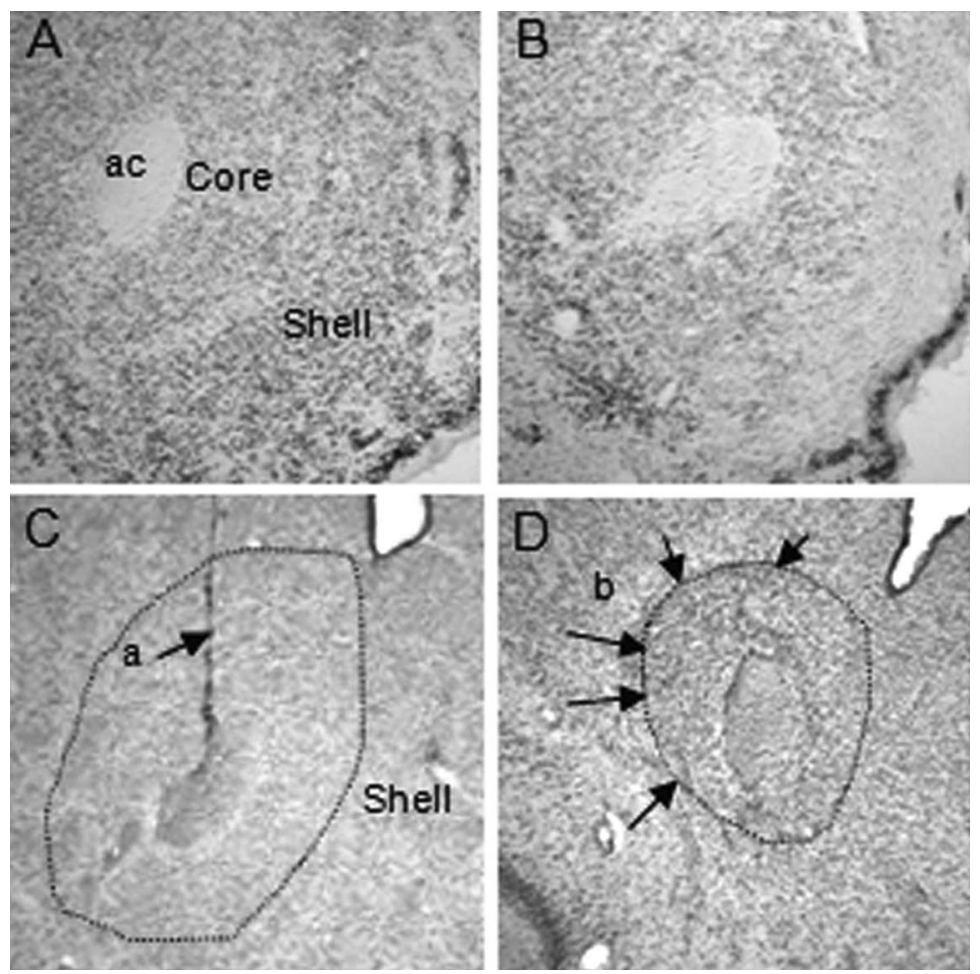

Figure 3. Representative photomicrographs of NeuN-stained and cresyl violet-stained coronal sections of rats with NAc shell, core lesions, or sham-operated controls. $A$, NeuN-stained section through the NAc region of a sham control rat, showing the region of the NAc shell, core, and anterior commissure (ac). B, NeuN-stained section of a NAc shell lesion, showing the complete loss of cell body NeuN immunoreactivity in the shell region and preservation of neurons in the core region. $\boldsymbol{C}$, Nissl-stained section of a NAC core sham rat showing the tract of the injector (a), as well as boundary of the NAc core. D, Nissl-stained section of a NAc core lesion; marked gliosis can be seen in the areas surrounding the anterior commissure. Marked shrinkage in area (b) dorsolateral to the commissure and the apparent medial shift of the anterior commissure are the result of the loss of neurons in the core region.
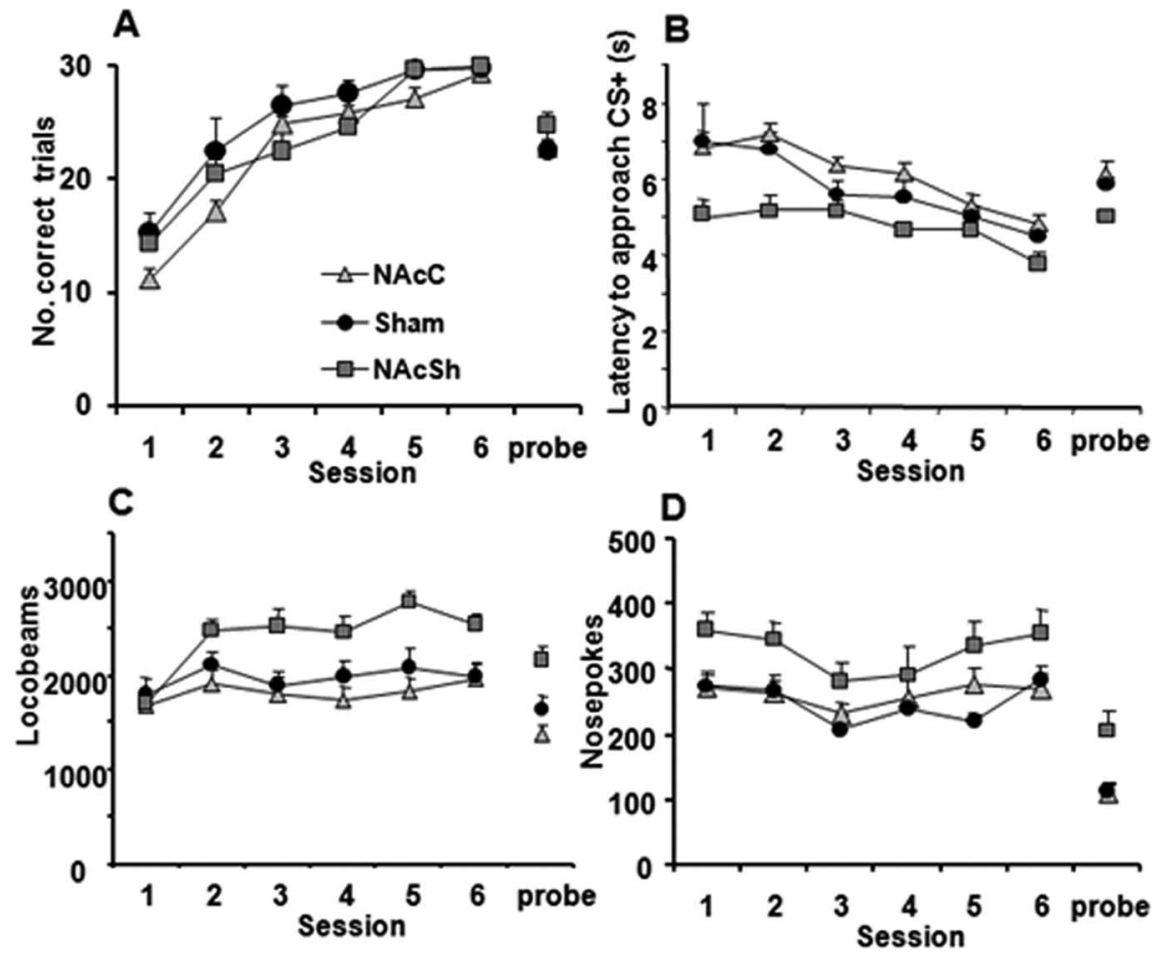

Figure 4. Mean \pm SEM performance of sham-operated controls and NAc core or shell lesion groups in discrete cue conditioning: $\boldsymbol{A}$, acquisition expressed as number of approaches to the $C S$ within $15 \mathrm{~s}$ (correct trial); $\boldsymbol{B}$, latency to approach $C S-U S$ in correct trials; $\boldsymbol{C}$, locomotor activity; $\boldsymbol{D}$, general nose-poke activity. NACC, NAc core; NAcSh, NAc shell. 
A
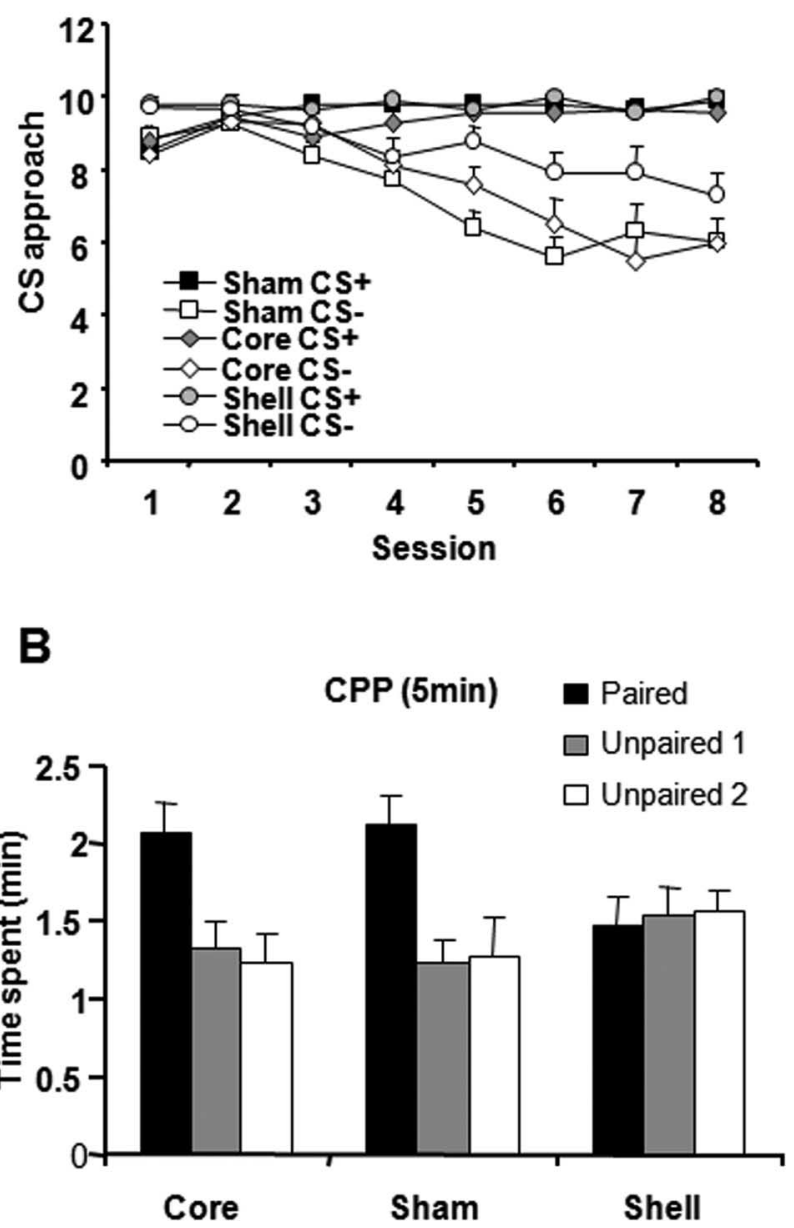

Figure 5. A, Mean \pm SEM performance in acquisition of place conditioning (context/placecue retrieval) after sham, NAc core, or shell lesions, expressed as number of approaches to $C S+$ and $C S-. \boldsymbol{B}$, Conditioned place preference (CPP) performance expressed as total time spent in each of the chamber (within a 5 min session) of sham controls, NAccore, and shell lesion groups.

discriminative approach behavior toward a CS+ and away from a CS - (Fig. 5A). NAc shell-lesioned, but not core-lesioned, rats were impaired in using place cues in guiding discriminative approach behavior toward a CS + while inhibiting approach to a CS-. Three-way ANOVA on all data revealed a significant main effect of CS $\left(F_{(1,25)}=91.16, p<0.0001\right)$, day $\left(F_{(7,175)}=19.16\right.$, $p<0.0001)$, and significant $\mathrm{CS} \times$ day interaction $\left(F_{(7,175)}=\right.$ $32.45, p<0.0001$ ), indicating that, across the $8 \mathrm{~d}$ of conditioning, rats reduced the number of approaches to the CS - while maintaining asymptotic numbers of approach to the CS+ within a session, across the $8 \mathrm{~d}$ of conditioning. There was also a significant main effect of lesion group $\left(F_{(2,25)}=4.78, p<0.02\right)$ and a significant CS $\times$ day $\times$ lesion interaction $\left(F_{(14,175)}=3.06, p<\right.$ $0.0001)$, as well as a trend toward CS $\times$ lesion interaction $\left(F_{(2,25)}\right.$ $=2.76, p<0.07$ ). Additional analyses showed these effects to be attributable to a significantly different pattern of acquisition of CS+/CS - discriminative approach behavior in the shelllesioned group compared with the sham group (CS $\times$ lesion interaction, $F_{(1,16)}=4.69, p<0.04$; day $\times$ lesion interaction, $\left.F_{(7,112)}=2.17, p<0.05\right)$, with Tukey's post hoc analyses revealing consistently higher levels of approach responses to the CS - in the shell-lesioned group across the $8 \mathrm{~d}$ of place conditioning $(p<$ $0.03)$. In contrast, two-way ANOVA of the acquisition perfor- mance of core-lesioned and sham-operated groups during place conditioning (Fig. 5A) showed no significant main effect of lesion $\left(F_{(1,18)}=0.001, p=0.97\right)$, nor any significant interactions involving lesion group $\left(\mathrm{CS} \times\right.$ lesion, $F_{(1,18)}=1.60, p=0.22$; day $\times$ lesion, $\left.F_{(7,126)}=0.93, p=0.48\right)$.

\section{Conditioned place preference}

As depicted in Figure 5B, the shell-lesioned group failed to show a significant preference for the paired place $\left(F_{(2,29)}=0.78, p=\right.$ 0.47 ), their performance being significantly different from that of the sham-operated group (place $\times$ lesion interaction, $F_{(2,32)}=$ $4.04, p<0.03$ ). All sham-operated and core-lesioned animals exhibited a strong preference for the paired place on the conditioned place preference test day, as indicated by the increased level of time spent in the place (chamber) associated with sucrose reinforcement compared with the two other unpaired places (core, $F_{(2,35)}=5.52, p<0.01$; sham, $F_{(2,29)}=7.40, p<0.003$ ). The performance of the two groups was not significantly different from one another (no lesion effect, $F_{(1,18)}=0.007, p=0.93$; no place $\times$ lesion interaction, $\left.F_{(2,36)}=1.07, p=0.35\right)$.

In summary, NAc shell-lesioned rats were significantly impaired in using place cues to retrieve appropriate CS information. This was accompanied by a failure of NAc shell-lesioned rats to acquire a conditioned preference for the place embedded with the CS-US association. In contrast, NAc core-lesioned rats were not impaired in using place cues for CS retrieval.

\section{Effect of HPC-NAc shell disconnection lesions on cue conditioning}

Two-way ANOVA comparing all four lesion groups (unilateral shell or HPC lesions, HPC-NAc shell disconnection lesion, and disconnection sham lesion) for the acquisition of discrete cue conditioning revealed a significant main effect of session $\left(F_{(5,110)}\right.$ $=226.4, p<0.0001$ ) attributable to an increase in the number of correct responses over the six conditioning sessions (Fig. 6A). There was no effect of any lesion on cue conditioning $\left(F_{(3,22)}=\right.$ $1.36, p=0.28$; no session $\times$ lesion interaction, $F_{(1,110)}=1.02, p=$ $0.43)$.

Levels of nose-poke behavior showed a general decline across the six conditioning sessions (main effect of session, $F_{(5,115)}=$ $3.98, p<0.002$ ) in all lesion groups (no lesion effect, $F_{(1,23)}=$ $1.61, p=0.21$; no session $\times$ lesion interaction, $F_{(15,115)}=1.14$, $p<0.33)$. General locomotor activity, however, increased across the six sessions (main effect of session; $F_{(5,115)}=36.35, p<$ 0.0001 ), but there were no differences in the levels and pattern of locomotor activity between groups (no lesion effect, $F_{(1,23)}=$ $2.30, p=0.10$; session $\times$ lesion interaction).

\section{Effect of HPC-NAc shell disconnection lesions on place conditioning}

Place-cue retrieval

Two-way ANOVA on the difference score data (Fig. $7 B$ ) revealed that, overall, rats acquired discriminated approach behavior toward a CS +, while reducing approach toward the CS - across the eight conditioning sessions (main effect of day, $F_{(7,161)}=65.28$, $p<0.0001)$, but there was a significant main effect of lesion $\left(F_{(3,23)}=5.13,0.007\right)$ and a day $\times$ lesion interaction $\left(F_{(21,161)}=\right.$ $2.27, p<0.01)$. Additional analyses showed that these effects were attributable to a significantly different pattern of acquisition of CS +/CS - discriminative approach behavior in the HPC-NAc shell disconnection lesion group compared with the disconnection sham group (day $\times$ lesion interaction, $F_{(7,77)}=3.83$, $p<$ 0.007 ; lesion effect, $\left.F_{(1,12)}=9.69, p<0.01\right)$. Separate analyses of 

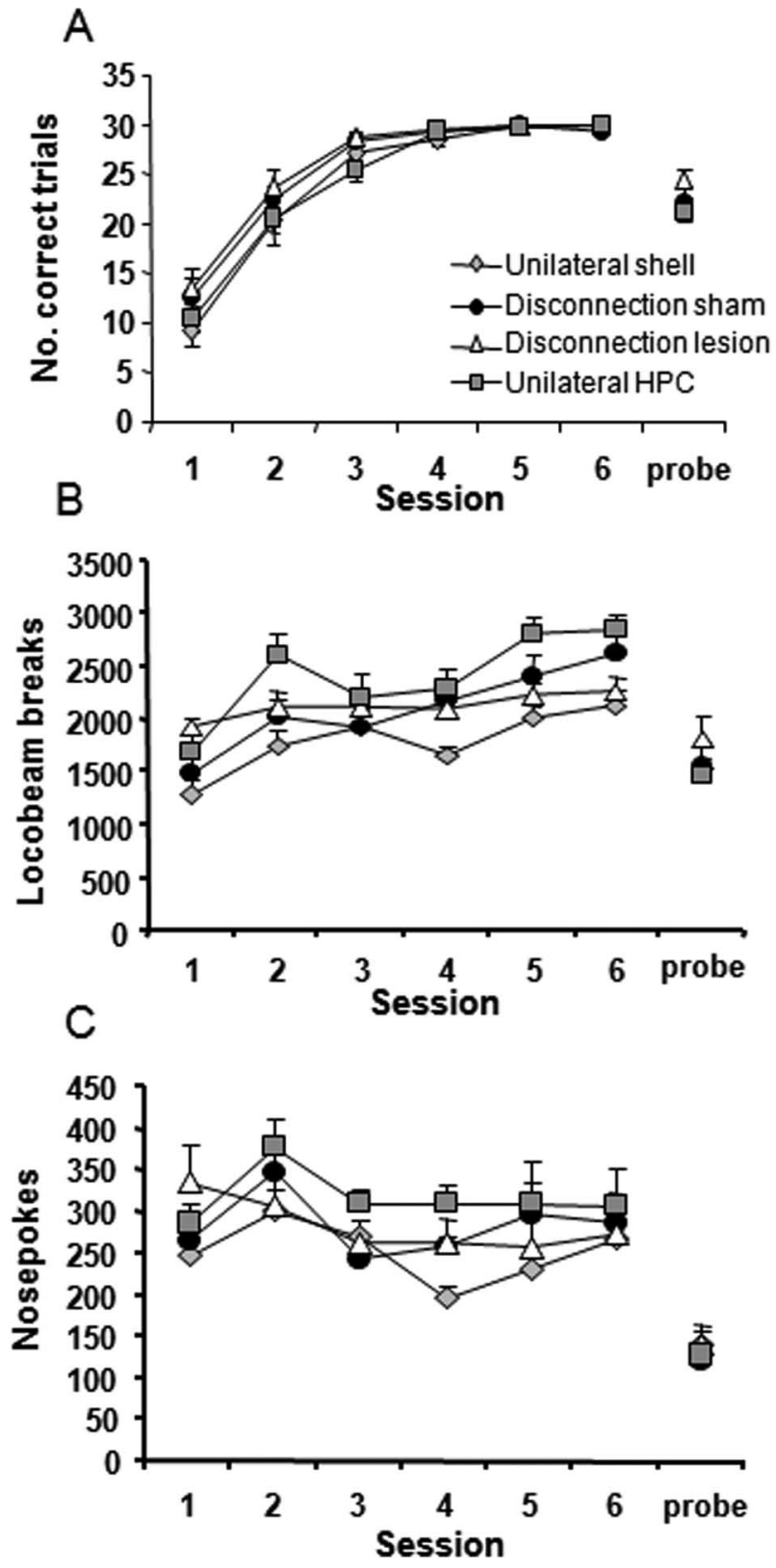

Figure 6. Mean \pm SEM performance of sham-operated controls and NAc core or shell lesion groups in discrete cue conditioning. $A$, Acquisition expressed as number of approaches to the $C S$ within $15 \mathrm{~s}$ (correct trial). B, Locomotor activity. C, General nose-poke activity.

the numbers of approaches made to the CS+ and CS - (Fig. 7A) confirmed that the disconnection lesioned rats emitted consistently higher levels of approach to the CS - compared with the disconnection sham rat group $\left(\mathrm{CS} \times\right.$ lesion interaction, $F_{(1,11)}=$ $9.69, p<0.01$; lesion effect, $\left.F_{(1,11)}=8.30, p<0.01\right)$. There was no difference in the pattern of acquisition of discriminative approach behavior between the unilateral shell-lesioned, unilateral HPC-lesioned, and disconnection sham groups (no lesion effect, $F_{(2,17)}=0.51, p=0.61$; no day $\times$ lesion interaction, $F_{(14,119)}=$ $0.90, p=0.56)$.

\section{Conditioned place preference}

The HPC-NAc shell disconnection lesioned rats failed to show a preference for the reward-associated spatial context, as indicated by the lack of significant difference in the time spent in the three places (Fig. 8) $\left(F_{(2,19)}=0.035, p=0.96\right)$, a pattern of behavior
A

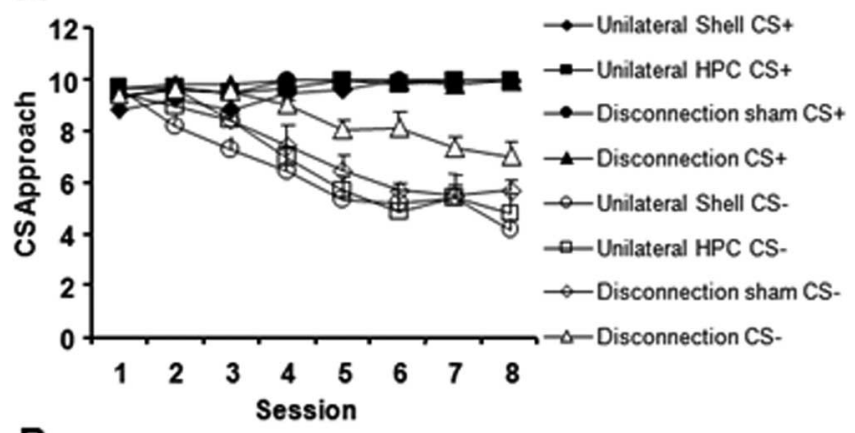

B

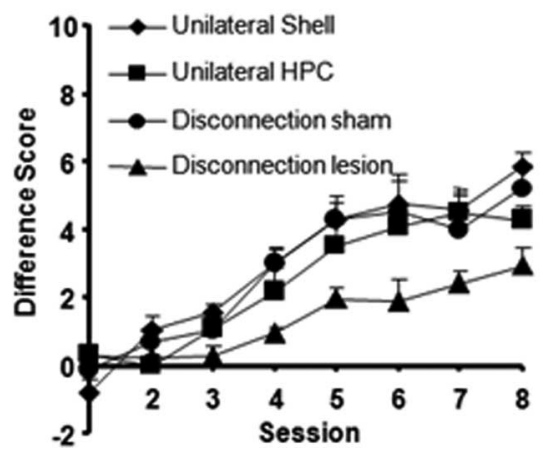

Figure 7. $A, B$, Mean \pm SEM performance in the acquisition of place conditioning (context/ place-cue retrieval) after disconnection sham, unilateral NAc shell, or HPC or disconnection lesions, expressed as number of approaches to $C S+$ and $C S-(\boldsymbol{A})$ or expressed as a difference score [number of approaches to $C S+-$ number of approaches to $C S-(B)]$.

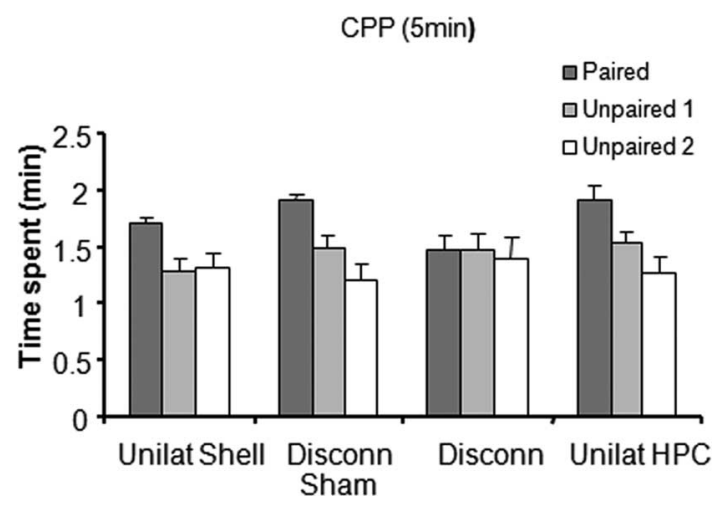

Figure 8. Conditioned place preference (CPP) performance expressed as the total time spent in each of the chamber (within $5 \mathrm{~min}$ ) of disconnection sham controls, unilateral NAc shell, or $\mathrm{HPC}$ and disconnection lesion groups.

significantly different from that of the disconnection sham group (place $\times$ lesion interaction, $F_{(2,22)}=3.32, p<0.05$ ). In contrast, unilateral HPC or NAc shell-lesioned and disconnection shamlesioned rats showed a significant preference for the place consistently paired with sucrose reward on the test day, as indicated by the increased level of time spent in the paired place compared with the two other unpaired places (unilateral shell, $F_{(2,23)}=5.41$, $p<0.01$; unilateral HPC, $F_{(2,16)}=5.82, p<0.01$; disconnection sham, $\left.F_{(2,17)}=7.07, p<0.007\right)$.

In summary, disconnection lesioned rats were significantly impaired in using place cues to retrieve associative information about a CS. This was evident in their failure to show conditioned preference for the place associated with the CS-US pairing. Their ability to acquire the CS-US association, however, remained intact. 


\section{Discussion}

The present results provide novel and strong evidence for an interaction between the HPC and NAc shell in the spatial contextual control of appetitive behavior. Bilateral excitotoxic lesions of the NAc shell markedly impaired appetitive conditioning to a reward-associated place, as well as the development of placefacilitated retrieval of CS information, mirroring the pattern of deficit produced by HPC lesions (Ito et al., 2006). Furthermore, we demonstrate for the first time a common functional circuitry in processing such spatial contextual information between the HPC and NAc shell, as evidenced by marked effects of HPC-NAc shell disconnection lesions that disrupt serial transfer of information between these two structures. The function of the HPC-NAc shell system contrasts with that underlying approach to discrete pavlovian cues that is dependent on the BLA and NAc core subregion.

\section{NAc shell and spatial contextual conditioning}

Excitotoxic lesions of the NAc shell produced impairments in the acquisition of spatial contextual conditioning and the use of spatial information to retrieve CS information, while sparing discrete cue conditioning, implicating the NAc shell in spatial context learning. The present data are consistent with aversive conditioning studies that show a failure of NAc shell-lesioned rats to acquire freezing to a conditioned context (Riedel et al., 1997; Jongen-Relo et al., 2003). Of the very few studies that have investigated the neural basis of appetitive contextual conditioning, one has shown the contradictory result of increased appetitive contextual conditioning after electrolytic lesions of the NAc shell (Cassaday et al., 2005). However, comparisons of these results with the present data are made difficult not only because of procedural differences, such as their use of electrolytic lesions, which are likely to have destroyed major fibers of passage, but also by the authors' observation that the flashing light stimulus (serving as the contextual stimulus) failed to gain significant associative strength in their appetitive trace conditioning task.

The observed impairments are also consistent with previous studies showing deficits in various forms of spatial learning, typically assessed by the radial arm maze, T-maze, and Morris water maze after disruption of neural processing in the NAc (Annett et al., 1989; Schacter et al., 1989; Sutherland and Rodriguez, 1989; Seamans and Phillips, 1994). However, there have been failures to observe spatial learning deficits after selective manipulations of the NAc shell involving the use of lidocaine (temporary inactivation) (Floresco et al., 1996) or excitotoxic lesions (Jongen-Relo et al., 2003). It has also been suggested that the NAc core, and not the shell, mediates spatial learning, because blockade of NMDA receptors in the NAc core lead to increased errors in the radial arm maze, reflecting a failure to transfer spatial information across trials (Smith-Roe et al., 1999). These discrepancies may arise because of subtle differences in the areas (and associated "neuronal ensembles" within these regions) that are disrupted by the manipulations (Pennartz et al., 1994). Aside from the fact that lidocaine also blocks neural activity of fibers of passage, thus preventing precise localization of the effect of the inactivation (Malpeli, 1999), neuroanatomical evidence suggests that the caudomedial region of the shell that is commonly destroyed in lesion studies receives glutamatergic input from the ventral HPC, whereas the more rostrolateral part of the NAc shell, and to a lesser extent the core, receives input from the dorsal HPC (Groenewegen et al., 1999). Accumulating evidence indicates a functional dichotomy within the HPC itself along the dorsoventral axis, with the dorsal HPC being more strongly implicated in spa- tial learning compared with the ventral HPC (Moser et al., 1993; Richmond et al., 1999; Pothuizen et al., 2004). Thus, the presence or absence of a spatial learning deficit after NAc shell lesions may depend on the extent to which the rostrolateral shell region is disrupted, in addition to the degree to which spatial control over behavior is maximized relative to that exerted by discrete sensory or motor cues. Detailed inspection of the size of the NAc shell lesion in the present study indicated that the lesions consistently extended to the medial parts of the rostrolateral shell, but such partial damage to the rostrolateral shell is unlikely to have been the sole explanation for the presence of a spatial deficit in this study.

It may be argued that the present deficits in the spatial context conditioning phase in the NAc shell-lesioned rats instead reflect the inability of these rats to facilitate behavioral switching. Indeed, a tendency to show perseverative responding, slower reversal learning, and extinction has been reported previously after cell body or dopamine-depleting lesions of the NAc (Robbins and Koob, 1980; Reading and Dunnett, 1991; Reading et al., 1991). Although we cannot entirely rule out this possibility, it is unlikely to be the sole explanation for the observed deficits as NAc shelllesioned rats were clearly impaired in their ability to associate a spatial context with reward presentation, as evident from their impaired performance in the conditioned place preference test. If perseverative responding or lack of extinction constituted the underlying deficit, the three compartments in the conditioned place preference test would have shown equally high levels of visiting, whereas our data actually showed a loss of place preference for the compartment previously paired with reward, reaching baseline levels that were characteristic for unpaired chambers.

\section{HPC-NAc shell interaction in spatial contextual conditioning} Disruption of serial communication between the NAc shell and HPC by combining unilateral, asymmetrical lesions of each structure in the present study produced impairments in contextdependent memory retrieval and place learning that were quantitatively and qualitatively similar to deficits produced by bilateral lesions of the NAc shell or HPC (Ito et al., 2006). Unilateral lesions of the NAc shell or HPC alone failed to produce any deficits in the same task, strongly indicating that the NAc shell and HPC are essential components of a neural pathway that mediates the effective formation of reward-associated contextual representations based on spatial information primarily gained from idiothetic (self-motion) cues. These data corroborate, as well as extend, Mogenson's initial hypothesis that the NAc-HPC pathway provides a way in which spatial information processed by the HPC can be "translated" into action via the NAc (Mogenson et al., 1980; Schacter et al., 1989), in proposing that it is specifically the NAc shell region that subserves this function.

Indeed, this notion is consistent with neuroanatomical findings of preferential targeting of the ventrolateral regions of the shell by projections from the HPC via the subiculum (Groenewegen et al., 1999; Voorn et al., 2004). Electrophysiological singleunit recordings have also found spatially sensitive cells in medial parts of the NAc that include the NAc shell and NAc shell/core boundary (Lavoie and Mizumori, 1994), areas that have been targeted for lesioning in the present study. Furthermore, our demonstration of a deficit in place-facilitated cue retrieval after caudomedial shell lesions is particularly in agreement with evidence that this region receives afferent input from both the BLA and HPC formation (Krettek and Price, 1978; Kita and Kitai, 1990; Groenewegen et al., 1999). 


\section{NAc core and BLA in discrete cue conditioning}

Excitotoxic lesions of the NAc core, and not the NAc shell, slowed the rate of acquisition of appetitive discrete cue conditioning, consistent with previous findings of decreased or impaired aversive discrete CS conditioning (conditioned suppression) after NAc core lesions (Parkinson et al., 1999a; Cassaday et al., 2005). Together with evidence that NAc core lesions impair the acquisition of autoshaping behavior in which repeated pairings of a CS and reward give rise to the acquisition of a pavlovian discriminated approach response to the CS + (Parkinson et al., 2000), the present results support the notion that the NAc core subserves appetitive pavlovian conditioning mechanisms and suggest that its role may be restricted to experimental conditions in which the CS is discrete.

The qualitative similarity in the pattern of effects produced by lesions of the NAc core and BLA in the present appetitive cue conditioning task agrees with previous evidence implicating a functional link between the NAc core and BLA in appetitive (Everitt et al., 1991; Cardinal et al., 2002) and aversive (Selden et al., 1991; Parkinson et al., 1999a) conditioning. Moreover, a recent study found a high degree of correlation in immediate early gene expression between the NAc core, BLA, and orbitofrontal cortex in rats that had been exposed to multiple cues previously associated with a highly palatable reward as opposed to rats that had been exposed to water-associated cues (Schiltz et al., 2007). Although the authors refer to the multisensory food-associated stimuli as a "contextual" cue, the apparent absence of any early gene expression in the HPC and NAc shell raises the possibility that each of these cues may have formed independent associations with the food reinforcer, making it likely that the predominant associative process in operation was BLA and NAc core dependent.

In conclusion, the present study provides evidence that the NAc core and shell represent two separate streams of appetitive information processing within a wider network of limbic-corticostriatal structures, a functional distinction that may not have been feasible in previous studies as most spatial-contextual paradigms made use of discrete cues to define a "context." We have circumvented this problem in the present experiment by using place preference chambers that are only discriminable by path integration, thus involving spatial navigational processing. We have identified a functional circuit involving the HPC and NAc shell that mediates spatial contextual control over conditioned approach behavior that operates alongside, or in competition with, other established functional circuits such as the BLA-NAc core pathway concerned with discrete stimulus control over pavlovian behavior (Everitt et al., 1991) and a BLA-orbitofrontal cortex pathway concerned with choice selection between expected outcomes (Baxter et al., 2000). As contextual control over approach responses to conditioned cues presumably requires an integration of spatial and discrete cue information, it is of particular note that NAc neurons processing converging BLA and HPC inputs have indeed been found in the caudomedial shell (Mulder et al., 1998; Floresco et al., 2001), the precise region targeted in the present lesion study. Overall, we found that an HPC-NAc shell pathway is necessary for place preference conditioning but only when the animal is forced to depend on spatial cues, which is not the case in conventional conditioned place preference paradigms that are more susceptible to discrete cue encoding (McDonald and White, 1993) and consequent engagement of the BLA-NAc core pathway (Everitt et al., 1991). This comparison serves to emphasize the likely competitive nature of processing at the limbic cortical-striatal interface.

\section{References}

Aggleton J (2000) The amygdala: a functional analysis, Ed 2. New York: Oxford UP.

Annett LE, McGregor A, Robbins TW (1989) The effects of ibotenic acid lesions of the nucleus accumbens on spatial learning and extinction in the rat. Behav Brain Res 31:231-242.

Baxter MG, Parker A, Lindner CC, Izquierdo AD, Murray EA (2000) Control of response selection by reinforcer value requires interaction of amygdala and orbital prefrontal cortex. J Neurosci 20:4311-4319.

Cador M, Robbins TW, Everitt BJ (1989) Involvement of the amygdala in stimulus-reward associations: interaction with the ventral striatum. Neuroscience 30:77-86.

Cardinal RN, Parkinson JA, Hall J, Everitt BJ (2002) Emotion and motivation: the role of the amygdala, ventral striatum, and prefrontal cortex. Neurosci Biobehav Rev 26:321-352.

Cassaday HJ, Horsley RR, Norman C (2005) Electrolytic lesions to nucleus accumbens core and shell have dissociable effects on conditioning to discrete and contextual cues in aversive and appetitive procedures respectively. Behav Brain Res 160:222-235.

Everitt BJ, Morris KA, O’Brien A, Robbins TW (1991) The basolateral amygdala-ventral striatal system and conditioned place preference: further evidence of limbic-striatal interactions underlying reward-related processes. Neuroscience 42:1-18.

Floresco SB, Seamans JK, Phillips AG (1996) Differential effects of lidocaine infusions into the ventral CA1/subiculum or the nucleus accumbens on the acquisition and retention of spatial information. Behav Brain Res 81:163-171.

Floresco SB, Seamans JK, Phillips AG (1997) Selective roles for hippocampal, prefrontal cortical, and ventral striatal circuits in radial-arm maze tasks with or without a delay. J Neurosci 17:1880-1890.

Floresco SB, Blaha CD, Yang CR, Phillips AG (2001) Modulation of hippocampal and amygdalar-evoked activity of nucleus accumbens neurons by dopamine: cellular mechanisms of input selection. J Neurosci 21:2851-2860.

French SJ, Totterdell S (2003) Individual nucleus accumbens-projection neurons receive both basolateral amygdala and ventral subicular afferents in rats. Neuroscience 119:19-31.

Gaffan D (1994) Dissociated effects of perirhinal cortex ablation, fornix transection and amygdalectomy: evidence for multiple memory systems in the primate temporal lobe. Exp Brain Res 99:411-422.

Gaffan D, Harrison S (1987) Amygdalectomy and disconnection in visual learning for auditory secondary reinforcement by monkeys. J Neurosci 7:2285-2292.

Gothard KM, Skaggs WE, McNaughton BL (1996) Dynamics of mismatch correction in the hippocampal ensemble code for space: interaction between path integration and environmental cues. J Neurosci 16:8027-8040.

Groenewegen HJ, Wright CI, Beijer AV, Voorn P (1999) Convergence and segregation of ventral striatal inputs and outputs. Ann N Y Acad Sci $877: 49-63$

Hirsh R (1974) The hippocampus and contextual retrieval of information from memory: a theory. Behav Biol 12:421-444.

Ito R, Everitt BJ, Robbins TW (2005) The hippocampus and appetitive Pavlovian conditioning: effects of excitotoxic hippocampal lesions on conditioned locomotor activity and autoshaping. Hippocampus 15:713-721.

Ito R, Robbins TW, McNaughton BL, Everitt BJ (2006) Selective excitotoxic lesions of the hippocampus and basolateral amygdala have dissociable effects on appetitive cue and place conditioning based on path integration in a novel Y-maze procedure. Eur J Neurosci 23:3071-3080.

Jongen-Relo AL, Kaufmann S, Feldon J (2003) A differential involvement of the shell and core subterritories of the nucleus accumbens of rats in memory processes. Behav Neurosci 117:150-168.

Kesner RP, Bolland BL, Dakis M (1993) Memory for spatial locations, motor responses, and objects: triple dissociation among the hippocampus, caudate nucleus, and extrastriate visual cortex. Exp Brain Res 93:462-470.

Kita H, Kitai ST (1990) Amygdaloid projections to the frontal cortex and the striatum in the rat. J Comp Neurol 298:40-49.

Krettek JE, Price JL (1978) Amygdaloid projections to subcortical structures within the basal forebrain and brainstem in the rat and cat. J Comp Neurol 178:225-254.

Lavoie AM, Mizumori SJ (1994) Spatial, movement- and reward-sensitive 
discharge by medial ventral striatum neurons of rats. Brain Res 638:157-168.

Malpeli JG (1999) Reversible inactivation of subcortical sites by drug injection. J Neurosci Methods 86:119-128.

McDonald RJ, White NM (1993) A triple dissociation of memory systems: hippocampus, amygdala, and dorsal striatum. Behav Neurosci 107:3-22.

McNaughton BL, Chen LL, Markus EJ (1991) “Dead reckoning," landmark learning, and the sense of direction: a neurophysiological and computational hypothesis. J Cogn Neurosci 3:190-202.

McNaughton BL, Battaglia FP, Jensen O, Moser EI, Moser MB (2006) Path integration and the neural basis of the "cognitive map." Nat Rev Neurosci 7:663-678.

Mogenson GJ, Jones DL, Yim CY (1980) From motivation to action: functional interface between the limbic system and the motor system. Prog Neurobiol 14:69-97.

Moser E, Moser MB, Andersen P (1993) Spatial learning impairment parallels the magnitude of dorsal hippocampal lesions, but is hardly present following ventral lesions. J Neurosci 13:3916-3925.

Mulder AB, Hodenpijl MG, Lopes da Silva FH (1998) Electrophysiology of the hippocampal and amygdaloid projections to the nucleus accumbens of the rat: convergence, segregation, and interaction of inputs. J Neurosci 18:5095-5102.

Muller R (1996) A quarter of a century of place cells. Neuron 17:813-822.

O’Keefe J (1999) Do hippocampal pyramidal cells signal non-spatial as well as spatial information? Hippocampus 9:352-364.

O'Keefe J, Nadel L (1978) The hippocampus as a cognitive map. Oxford: Oxford UP.

Packard MG, Hirsh R, White NM (1989) Differential effects of fornix and caudate nucleus lesions on two radial maze tasks: evidence for multiple memory systems. J Neurosci 9:1465-1472.

Parkinson JA, Robbins TW, Everitt BJ (1999a) Selective excitotoxic lesions of the nucleus accumbens core and shell differentially affect aversive Pavlovian conditioning to discrete and contextual cues. Psychobiology $27: 256-266$.

Parkinson JA, Olmstead MC, Burns LH, Robbins TW, Everitt BJ (1999b) Dissociation in effects of lesions of the nucleus accumbens core and shell on appetitive pavlovian approach behavior and the potentiation of conditioned reinforcement and locomotor activity by D-amphetamine. J Neurosci 19:2401-2411.

Parkinson JA, Willoughby PJ, Robbins TW, Everitt BJ (2000) Disconnection of the anterior cingulate cortex and nucleus accumbens core impairs Pavlovian approach behavior: further evidence for limbic cortical-ventral striatopallidal systems. Behav Neurosci 114:42-63.

Paxinos G, Watson C (1997) The rat brain in stereotaxic coordinates, Ed 2. New York: Academic.

Pennartz CM, Groenewegen HJ, Lopes da Silva FH (1994) The nucleus accumbens as a complex of functionally distinct neuronal ensembles: an integration of behavioural, electrophysiological and anatomical data. Prog Neurobiol 42:719-761.

Pezze MA, Feldon J, Murphy CA (2002) Increased conditioned fear response and altered balance of dopamine in the shell and core of the nucleus accumbens during amphetamine withdrawal. Neuropharmacology 42:633-643.

Pothuizen HH, Zhang WN, Jongen-Relo AL, Feldon J, Yee BK (2004) Dis- sociation of function between the dorsal and the ventral hippocampus in spatial learning abilities of the rat: a within-subject, within-task comparison of reference and working spatial memory. Eur J Neurosci 19:705-712.

Reading PJ, Dunnett SB (1991) The effects of excitotoxic lesions of the nucleus accumbens on a matching to position task. Behav Brain Res 46:17-29.

Reading PJ, Dunnett SB, Robbins TW (1991) Dissociable roles of the ventral, medial and lateral striatum on the acquisition and performance of a complex visual stimulus-response habit. Behav Brain Res 45:147-161.

Richmond MA, Yee BK, Pouzet B, Veenman L, Rawlins JN, Feldon J, Bannerman DM (1999) Dissociating context and space within the hippocampus: effects of complete, dorsal, and ventral excitotoxic hippocampal lesions on conditioned freezing and spatial learning. Behav Neurosci 113:1189-1203.

Riedel G, Harrington NR, Hall G, Macphail EM (1997) Nucleus accumbens lesions impair context, but not cue, conditioning in rats. Neuroreport 8:2477-2481.

Robbins TW, Koob GF (1980) Selective disruption of displacement behaviour by lesions of the mesolimbic dopamine system. Nature 285:409-412.

Schacter GB, Yang CR, Innis NK, Mogenson GJ (1989) The role of the hippocampal-nucleus accumbens pathway in radial-arm maze performance. Brain Res 494:339-349.

Schiltz CA, Bremer QZ, Landry CF, Kelley AE (2007) Food-associated cues alter forebrain functional connectivity as assessed with immediate early gene and proenkephalin expression. BMC Biol 5:16.

Schroeder JP, Wingard JC, Packard MG (2002) Post-training reversible inactivation of hippocampus reveals interference between memory systems. Hippocampus 12:280-284.

Seamans JK, Phillips AG (1994) Selective memory impairments produced by transient lidocaine-induced lesions of the nucleus accumbens in rats. Behav Neurosci 108:456-468.

Selden NR, Everitt BJ, Jarrard LE, Robbins TW (1991) Complementary roles for the amygdala and hippocampus in aversive conditioning to explicit and contextual cues. Neuroscience 42:335-350.

Setlow B, McGaugh JL (1999) Differential effects of immediate posttraining sulpiride microinfusions into the nucleus accumbens shell and core on Morris water maze retention. Psychobiology 27:248-255.

Setlow B, Holland PC, Gallagher M (2002) Disconnection of the basolateral amygdala complex and nucleus accumbens impairs appetitive pavlovian second-order conditioned responses. Behav Neurosci 116:267-275.

Smith-Roe SL, Sadeghian K, Kelley AE (1999) Spatial learning and performance in the radial arm maze is impaired after $N$-methyl-D-aspartate (NMDA) receptor blockade in striatal subregions. Behav Neurosci 113:703-717.

Squire LR (1986) Mechanisms of memory. Science 232:1612-1619.

Squire LR, Knowlton B, Musen G (1993) The structure and organization of memory. Annu Rev Psychol 44:453-495.

Sutherland RJ, Rodriguez AJ (1989) The role of the fornix/fimbria and some related subcortical structures in place learning and memory. Behav Brain Res 32:265-277.

Voorn P, Vanderschuren LJ, Groenewegen HJ, Robbins TW, Pennartz CM (2004) Putting a spin on the dorsal-ventral divide of the striatum. Trends Neurosci 27:468-474. 